\title{
LA COMUNIDAD FEMENINA Y LA SABIDURÍA POPULAR EN "ÚLTIMO AQUELARRE" DE JULIETA DOBLES
}

Jorge Chen Sham

\begin{abstract}
RESUMEN
"Último aquelarre" hace, de la doble diferencia biológica e histórica sobre la cual se ha fundado el sistema de exclusiones, un testimonio de la posibilidad de construcción de una ética que construya una nueva intersubjetividad femenina. Su primer paso es la conciencia de pertenecer a una comunidad de mujeres, con un señas de identidad particulares y un conocimiento que pueda ser transmitido. Como la visión cristiana ha permeado la idea que actualmente manejamos del "aquelarre" haciéndolo sinónimo de culto satánico, Julieta Dobles reivindica su sentido arcaico: el aquelarre es celebración de los poderes del cosmos y se refiere a la reunión en plenilunio hecha por mujeres que celebran ritos y cantos para convocar a las fuerzas de la naturaleza.
\end{abstract}

Palabras clave: Julieta Dobles, poesía costarricense, aquelarre, matriherencia, comunidad femenina.

\begin{abstract}
The Last Witches' Sabbath makes, of the double difference, both biological and historical on which has been founded the system of exclusions, a testament of the posibility of constructing an ethic, that constructs a new feminine intersubjective. The first step is the consciousness that pertains to the community of women, with its particular identifying signs and an understanding that can be transmitted. Like the Christian vision has spread the idea that we currently manage of the witches' sabbath, making it synonomous with the Satanic cult. Julieta Dobles "is blind to" to her archaic feelings, the witches' sabbath is a celebration of the powers of the cosmos and makes reference to the meetings in the full moon made by women who celebrate the rites and songs in order to convene the forces of nature.
\end{abstract}

Key words: Julieta Dobles, Costa Rican Poetry, witches' sabbath, community of women.

Para oponerse al concepto de patrimonio, en cuanto legado o bienes heredados del padre $^{1}$, las teorías del género actuales crean el constructo "matriherencia", de manera que confirman el derecho de las mujeres a un "patrimonio", ya que a la mujer se le negaba los derechos fundiarios de legar bienes.

La matriherencia remite a un tipo de legado que el falocentrismo no acepta; destaca la memoria histórica de las mujeres, por lo que resume colectivamente lo dado y creado por la mujer dentro de un herencia histórica y genérica. La matriherencia se convierte en una

Dr. Jorge Chen Sham. Profesor de la Escuela de Filología, Lingüística y Literatura, Universidad de Costa Rica. San Pedro, San José, Costa Rica

Correo electrónico: jorgec@le.ucr.ac.cr 
estrategia para legitimar y reivindicar el derecho de las mujeres a un saber y el diseño de una subjetividad a la que corresponde tal estrategia. Es decir, siguiendo la terminología foucauldiana para el análisis discursivo, la arqueología que apunta hacia la doble diferencia biológica e histórica sobre la cual se ha fundado el sistema de exclusiones desemboca forzosamente en la construcción de una ética que construya una nueva intersubjetividad femenina. Su primer paso es la conciencia de pertenecer a una comunidad de mujeres, con unas señas de identidad particulares y un conocimiento que pueda ser transmitido.

A ello responde el poema "Último aquelarre" de Julieta Dobles ${ }^{2}$, perteneciente al poemario Los delitos de Pandora (1986). Como la visión cristiana ha permeado la idea que actualmente manejamos del "aquelarre", haciéndolo sinónimo de culto satánico, ya que sale un macho cabrío que, para algunas tradiciones, representa al demonio, debemos comenzar por aclarar que, en su sentido arcaico, el aquelarre es una celebración de los poderes del cosmos y se refiere a la reunión en plenilunio hecha por mujeres que celebran ritos y cantos para convocar a las fuerzas de la naturaleza ${ }^{3}$.

Retomando la distinción propuesta por Julio Caro Baroja, entre las dos prácticas de las artes ocultas, la hechicería correspondería a un arte solitario, mientras que la brujería a un culto comunitario (1961: 126). Las prácticas del ocultismo se caracterizan, sobre todo, por su respeto a las fuerzas del cosmos, al culto a los poderes que emanan de la tierra y del saber que ello conlleva; por ejemplo, el nacimiento y la muerte, la fertilidad de la tierra, la cocina y la curación de las enfermedades del alma o del cuerpo (Hutchinson 1992: 128). Por ello, la brujería se presenta como un saber de raigambre femenino, cuya transmisión se efectúa en un contexto en el que el estudio de las hierbas y de brebajes emanan de las fuerzas de la naturaleza. "Último aquelarre" de Julieta Dobles convoca la pertinencia de esa comunidad femenina reunida para realizar ritos celebratorios en honor a la madre tierra, con la que se identifica, desde el principio del poema, el sujeto colectivo; el inicio de "Último aquelarre" insiste en el punto de llegada en un movimiento que involucra la movilización y el poder de convocatoria:

Hemos venido todas/ las de las manos mágicas (vv.1-2).

La conciencia de grupo radica en esa necesidad de pertenencia que posibilita el epíteto con carácter restrictivo "las de las manos mágicas", pues se refiere a una parte dentro del género femenino con esta característica especial. Según Chevalier, las manos "expresan la idea de actividad, trabajo al mismo tiempo que la de potencia, dominio" (1995: 682), de manera que el sujeto femenino se reconoce en el poder creador de unas manos que son sinécdoque del quehacer y de sus capacidades como brujas. Su identificación con los secretos de la naturaleza y el dominio-uso que hagan de ellos se describe en el adjetivo "mágicas"; estas mujeres poseen un don especial que comparten; esa capacidad visionaria y de receptividad las ha conducido, bajo el signo de la convocatoria general, a un ágape de ritos ancestrales en los que dominan la fogata y la luna llena:

Tú nos has conjurado, / y al exacto poder de la palabra

nos hemos reunido, como antaño, / en la noche la luna silente

y del calor del fuego receloso (vv. 3-7).

Ellas han escuchado el mensaje que las interpela hic et nunc, como ha sucedido en otras ocasiones. Los versos 5 al 7 ubican temporal y espacialmente el lugar de la reunión, 
insistiendo con el complemento circunstancial "como antaño" en un tiempo remoto, algo que sucedió in illo tempore y que se repite cíclicamente. Las hechiceras vienen a reunirse en el aquelarre, en un acto que, al repetirse constantemente cada vez que haya luna llena ("la luna silente"), destaca la idea de regeneración del cosmos gracias al fuego purificador ${ }^{4}$. Se trata de una memoria histórica que se renueva constantemente, como si el aquelarre se convirtiera en un celebración que refuerza la identidad, los vínculos de la pertenencia.

Por lo anterior, el poema es palabra ritual que celebra los lazos de la comunidad femenina y "Último aquelarre" de Julieta Dobles reivindica, por partida doble, el poder de convocatoria de la Poesía con la clarividencia del conjuro que hace de estas mujeres sensibles y receptivas a la palabra. Pero, además, sugiere el camino iniciático de las duras pruebas. Tal vez por ello las sinécdoques "luna silente" y "fuego receloso" impliquen la idea de apartarse del mundo para que no las vean y las juzguen los hombres, lo cual desarrolla la siguiente unidad como el origen de un sufrimiento que se grafica en la imagen del castigo:

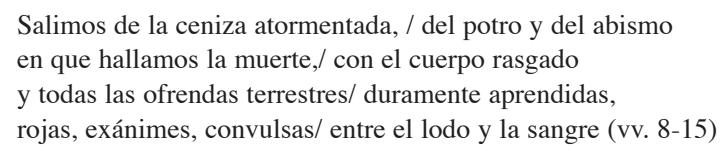

El punto de partida es la conciencia del sufrimiento y del dolor que ha provocado la persecución histórica de las mujeres que han practicado la hechicería. La sinécdoque "ceniza atormentada" señala el principal castigo que la Inquisición daba a las "brujas": la hoguera se convierte en el suplicio principal con el cual se lograba el exterminio y se negaba su diferencia radical; pero existen otros métodos de tortura y están nombrados en el verso 9. Insisten en la imagen del desmembramiento y fragmentación del cuerpo torturado ("cuerpo rasgado") y en la destrucción del saber heredado con la sinécdoque "ofrendas terrestres" (v. 12), las cuales implican los dones o facultades que les han sido encomendados y guardados en una sabiduría, ahora echada por el piso, al mismo tiempo pisoteada ("el lodo") y destruida ("sangre"). La persecución y el sufrimiento del sujeto colectivo permiten el reconocimiento de que, con la superación de esta situación de injusticia (“[s]alimos de...”), se adquiere la conciencia del odio y del temor que arrastran a cualquier tipo de fanatismo; por ello, el poema convoca un movimiento que señala tanto el punto de partida del periplo, fiel trasunto de la experiencia histórica de las marginadas por ser hechiceras en el verso 8, como el punto de llegada de ese éxodo liberador que las congrega en tanto asamblea:

Hemos venido todas $($ v.1) $\Leftarrow$ Salimos de la ceniza atormentada (v. 8)

Señalemos, en primer lugar, que la repetición de la misma estructura sintáctica (ya que hay sólo un verbo conjugado del cual dependen todos los complementos) remite a la forma de un conjuro, por lo que podemos afirmar que "Último aquelarre" en sí mismo es la oración mágica gracias a la cual se ejerce el poder de la palabra que convoca y reivindica; es el recordatorio de la identidad colectiva y el conjuro mágico que devuelve a este "nosotros" su memoria. La comunidad se logra aquí en el reconocimiento de un saber compartido que, en los versos 12-13 se presenta como unas facultades en las que han debido ejercitarse afanosamente hasta dominar las destrezas y las técnicas de su campo: "todas las ofrendas terrestres/ duramente aprendidas". La tercera unidad explicita en qué consiste este saber: 


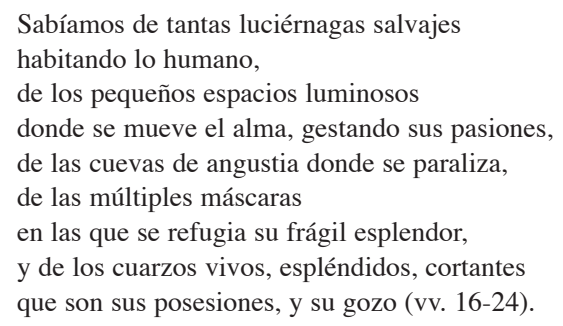

Consiste en el conocimiento cabal del interior del ser humano. La metáfora de la luz invade este saber de las hechiceras con la equivalencia paradigmática entre "tantas luciérnagas salvajes" (v. 16) y "los pequeños espacios luminosos" (v. 18). Esta equivalencia subraya esa capacidad que tienen las hechiceras para auscultar los lugares más recónditos del hombre y penetrar en las profundidades del alma (v.19). Por esta razón, el hablante colectivo tiene conciencia de que posee una instrucción y una competencia que lo habilita para entrar en lo que está oculto o de difícil acceso para los no iniciados. Saber develar los secretos del hombre: en ello radica el aprendizaje de la naturaleza y de las fragilidades humanas.

Así, estas hechiceras, tal y como lo hace la Celestina, conocen al detalle las pasiones humanas. El inventario realizado apunta hacia los dos tipos de sentimientos que suscitan las pasiones en el hombre: por un lado, su fragilidad se connota en aquello que le acarrea sufrimientos, angustias o miedos; por otro, su vulnerabilidad se detecta en lo que puede suscitar sus alegrías y satisfacciones más íntimas. No cabe mejor recuento del saber femenino como estrategia reivindicatoria que la identidad compartida y celebrada en el poema.

De esta manera, la invocación que acompaña el conjuro va trazando la historia colectiva de un sufrimiento y de una lucha que es interpretada como el recordatorio de la salvación posible. Dicho de otra manera, "Último aquelarre" es el testimonio colectivo de una situación de injusticia y de persecución, la cual es vivida como una prueba iniciática de la que han salido conscientes de su condición subalterna (marginal) y de la opresión histórica a la que han sido sometidas las hechiceras.

Si la primera estrofa del poema recuerda el poder de convocatoria gracias a la palabra poética (el encuentro posible bajo plenilunio), la segunda estrofa pondera el triunfo sobre el terror de los vejámenes inquisitoriales, que intentaban destruirlas quemando o torturando sus cuerpos. La Inquisición destruía sus cuerpos procurando acabar con la herejía y las prácticas de hechicería. Sin embargo, es su conocimiento del cosmos lo que les permitirá salir victoriosas de esta dura prueba. Por ello, la tercera estrofa interpela el sentido de la comunidad mediante la explicitación de una identidad lograda en el saber compartido; mientras que la estrofa siguiente recuerda el origen de los dones recibidos; es decir, la procedencia de todas las dotes y facultades que han aprendido se interpreta como un llamado con carácter sacerdotal:

\footnotetext{
Fueron nuestros los árboles/ verdes santuarios, altas cúpulas vivas y sagradas,

las hierbas que nos llaman/ con su puntal de aromas

y su humildad de oculto sacerdocio

sobre los anchos dones de la vida,/ la salud o la muerte (vv. 25-32).
} 
Observemos entonces el movimiento al que nos invita esta estrofa. En la óptica de "Último aquelarre", el presente del acto poético plantea el regressus ad uterum, ese lugar en donde las hechiceras se iniciaron en sus artes y al cual regresan, como indica la primera estrofa. El bosque no solo es el lugar de aprendizaje para hechicería, sino que también imprime y proporciona el germen de un saber que despierta sensaciones olfativas; el dominio del herbolario faculta el ejercicio de su saber e identifica su origen ("su humildad de oculto sacerdocio", v. 30). El bosque es visto como un gran templo o santuario que da abrigo y protege a las hechiceras; se convierte en el lugar sagrado en donde aprenden el secreto de las plantas y de las hierbas con el que podrán ejercer el arte de la curación y conocer aquello que domina la existencia del hombre mismo, la naturaleza. No es inocente tal correlación: desde un punto de vista mítico-simbólico, la regeneración de la naturaleza, de sus ritmos y de sus movimientos está relacionado con los ciclos de la mujer.

El credo colectivo se transforma en acción que permite, en la concientización del sufrimiento colectivo, la liberación por medio de la palabra poética; su eficacia y su poder salvífico quedan testimoniados en su instrumentalización práctica y ritual, porque rompe con las cadenas y pregona el cambio con el conjuro, potente y mágico, desarrollado en la primera estrofa de la cuarta unidad:

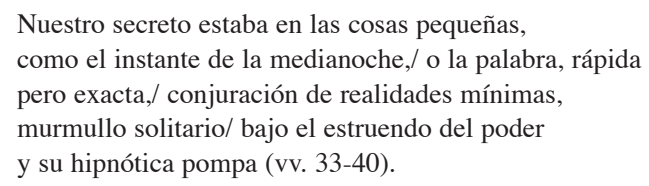

El sujeto colectivo redescubre el poder de la palabra en el aquelarre ensordecedor que rompe el silencio de la noche. El conjuro performa la realidad y la transforma en una temporalidad fugaz propia a la celebración del rito, en una metamorfosis en la que lo desapercibido al ojo humano, es decir lo sobrenatural y lo ignorado, cobra vida con las "cosas pequeñas" (v. 33) y con las "realidades mínimas" (v. 37). Los versos 38 ("murmullo solitario") y 39 ("el estruendo del poder") explican el efecto de la letanía sobre las participantes del aquelarre con imágenes auditivas que ponderan el poder de la palabra dicha en el marco de la imprecación religiosa"; son metonimias del conjuro y su eficacia se advierte en el último verso, pues "su hipnótica pompa" (v. 40) traduce esa capacidad mágica para mantener en vilo y en estado de trance colectivo, gracias a la emergencia de unos gestos y unos actos ritualizados. Por ello, "su hipnótica pompa" se refiere a la procesión solemne y a la liturgia que producen una letanía cargada de un poder al mismo tiempo persuasivo y transcendental. No cabe mayor descripción de lo que es la esfera ilocutiva del lenguaje.

El aquelarre se transforma en discurso epidíctico; en él se reconoce la comunidad, en él se afianzan los lazos identitarios y se renueva, en el espacio de la fiesta, el origen mismo de la hechicería. De ahí el sentido de las preguntas que sirven para interpelar a las participantes del aquelarre como recordatorio de un saber ancestral:

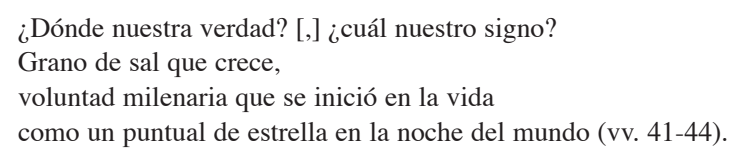


La respuesta confirma el legado femenino; la matriherencia surge para redinamizar esa voluntad de conciencia con la que se identifica el saber de la hechicería y se justifica la emergencia del aquelarre. El sentimiento de pertenencia queda dramatizado en las dos preguntas; su respuesta esclarece la voluntad de unión y de solidaridad con las que nace este saber de raigambre eminentemente femenino. Por ello, la metáfora evangélica del "grano de sal" (v. 42) insiste en el poder de convocatoria, en esa capacidad para interpelar y crear vida gracias a ese don maravilloso y exclusivo que detentan ellas desde los orígenes mismos del universo. La aposición explicativa de los versos 43-44 insiste en el acto fundacional que hace posible la creación de un saber femenino con un conocimiento sui generis, por lo que se continúa con el credo colectivo empezado en los versos 33 al 40:

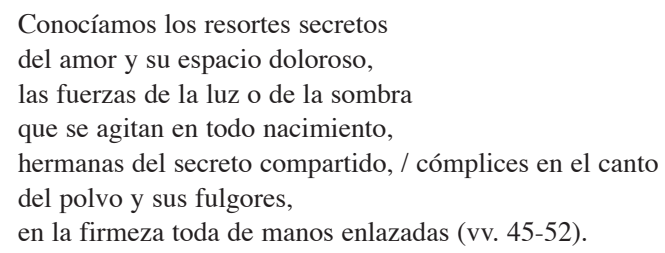

Al reforzar el carácter colectivo del saber, el sujeto comunitario apela a la hermandad y a la fraternidad como sello característico de toda empresa de conocimiento, de una práctica compartida (Hutchinson 1992: 129) y una experiencia idéntica y plural, de manera que entrelaza, en el ámbito de los afectos, opuestos que delimitan las fronteras de praxis: "del amor"/ "su espacio doloroso", "de la luz/ de la sombra" y "el canto del polvo"/ "sus fulgores"6. El credo termina reforzando la invocación inicial a la unión del sujeto femenino, en una posición irrenunciable e intransigente en cuanto a su identidad:

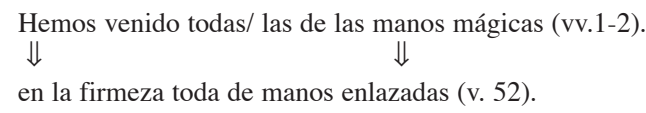

El conjuro llega a su fin y el tiempo del ágape alcanza su clímax, al dar paso al elogio de esa fuerza salvífica que reúne a todas los creyentes bajo el alero del "poder" fecundador y creador:

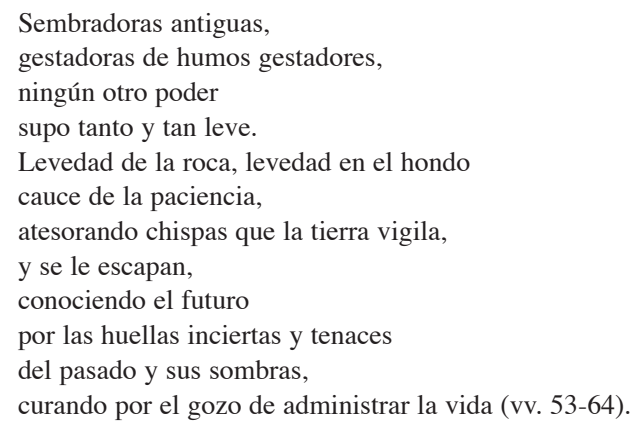


La correlación entre conocimiento y poder resurge para reafirmar la capacidad de este sujeto colectivo para fecundar con la equivalencia entre las frases nominales "[s]embradoras antiguas" y "gestadoras de humos"; sembrar y gestar son dos movimientos complementarios de un mismo proceso que da vida a los seres o a las cosas. Esto no es casual: todo el poema insiste en las características propias de este saber profundo, es decir, arcaico porque se remonta a los inicios del tiempo, telúrico porque tiene asiento en el "humo" creador, cósmico porque indaga en los lugares más secretos del planeta, humano porque ausculta el alma del hombre, transcendente porque eleva al hombre que siente abandonar su cuerpo. Precisamente, la aparición de los oximorones, "levedad de la roca, levedad en el hondo" (v. 57), da cuenta del poder sobrenatural y maravilloso que el sujeto femenino aprende, pues el contraste y la conjunción entre la ligereza y la pesadez acentúan que ese poder de la hechichería metamorfosea las cosas y las hace aparecer con una nueva esencia; se trata de un conocimiento transformador, enunciado en una triple acción con los gerundios siguientes:

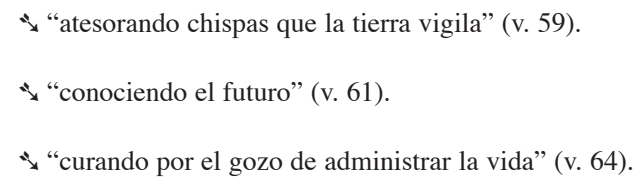

El aprendizaje femenino de la hechicería se resume en la celebración de un saber que guarda, con cuidado y con estima, los secretos de la fertilidad, de la vida y del tiempo. De manera que, en su clímax, "Último aquelarre" refuerza la comunidad de saber posibilitada en el carácter epidíctico del discurso, orientado hacia el elogio y la identificación de quien comparte tanto la misma opinión como la misma experiencia de vida (Gumbrecht 1979: 365). Ello refuerza la identidad colectiva en el marco de la cohesión de grupo:

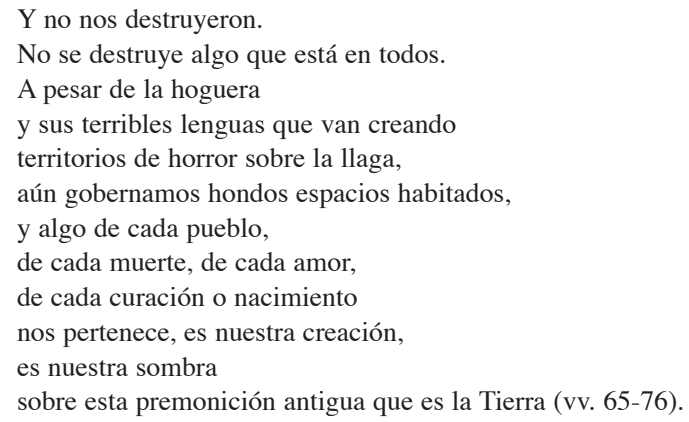

La superación de la prueba a la que se refiere el poema posee resonancias históricas; el verbo "destruir" subraya la posición intransigente de la Inquisición ante los fenómenos religiosos heterodoxos, como son los alumbrados y las prácticas de la hechicería y brujería ${ }^{7}$. Las vejaciones de la Inquisición se materializaban en la práctica de los castigos corporales y mentales a partir de la tortura y la reclusión en las celdas de la Inquisición, respectivamente en la sinécdoque "territorios de horror sobre la llaga" o en la metonimia "hondos espacios habitados". Una vez sentenciados, los ajusticiados eran condenados a morir en la hoguera; éste era el máximo castigo para los acusados de herejía (Kamen 1985: 247), cuya ejecución se hacía en los auto de fe para que sirvieran de escarnio público ${ }^{8}$. En el caso de las brujas, desde que 
en 1484 el papa Inocencio XIII promulga la bula Summis desiderantes (Chinchilla 1998: 139), su cacería y persecución se vuelven razón de Estado y obligación de todo cristiano. La Inquisición se dedicará a combatir la brujería, asociada a partir de ahí oficialmente a lo demoníaco, y se acusará a las brujas de crímenes tan oprobios como el infanticidio y las bacanales orgiásticas, por lo que es necesario eliminarlas ${ }^{9}$. La ejecución en la hoguera ha pasado a ser la forma por excelencia por la que, en nuestro imaginario occidental, se extermina a las "brujas" y "Último aquelarre" inserta esta experiencia de sufrimiento y de negación de la condición femenina en el testimonio colectivo de quienes viven el mismo dolor y la misma injusticia (Prada 1990: 37-8), pero que superan, con su entereza, todos los obstáculos y las pruebas.

De esta manera, en "Último aquelarre", el sujeto colectivo hace, de la quema de brujas por miedo e intolerancia, el pilar de su estrategia liberadora. El reconocimiento de que tal experiencia de sufrimiento jamás aniquiló su saber, aunque trataron de exterminarlas, es un signo de comunión y de identidad del legado ancestral que salvaguarda su conocimiento; de ahí la afirmación categórica del verso 74: "nos pertenece". Ese saber sobre el hombre y el mundo jamás pudo ser destruido, porque permanece y se mantiene incólume en lo más profundo de sus corazones y pasa de generación en generación. Aquí se produce el remate final en el cierre del poema, interesantísimo porque "Último aquelarre" realiza una equivalencia que, solamente dentro de una conciencia matrilineal, puede comprenderse, al reivindicar el origen telúrico y arcaico de ese saber en la mujer, la única que puede crear y dar forma. Esta afirmación se transforma en un rito celebratorio, gracias al cual "Último aquelarre" se hace imprecación comunitaria de un "nosotras femenino", que canta los grandes secretos de la vida:

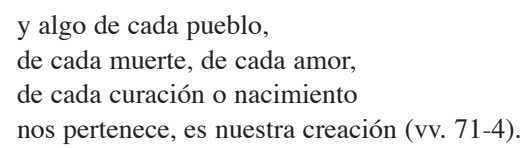

La significación del poema debe asociarse, entonces, al culto de la Gran Madre, el cual "respondía a la proclamación de la preponderancia femenina en las sociedades ancestrales" (Balcells 2003: 177) ${ }^{10}$. La vida se prolonga en cada una de las mujeres, está signado en todo lo que de ellas emana; el privilegio y el poder de crear no se pueden "destruir". El vínculo con la Tierra, la fuente creadora y regeneradora por excelencia, acaba siendo el vínculo indisoluble que une la mujer a lo telúrico: dar fruto y dar la vida son aquí sinónimos. Estos versos finales de "Último aquelarre" reafirman la esencia femenina; en ello estriba la matriherencia que se prolonga en cada ser vivo, con el ensanchamiento del radio de acción o el lugar de influencia del sujeto femenino sobre la sociedad y sobre el planeta. El aquelarre, con su poder de convocatoria de ese saber femenino, nos recuerda el origen arcano de la vida, en donde se manifiesta la relación del hombre con la sacralidad del mundo. Occidente ha confinado la brujería y a las mujeres que practican ese saber a una marginalidad histórica; la conciencia subalterna en Julieta Dobles posibilita que aquélla proyecte una reivindicación política y sea instrumento para la identificación solidaria de las mujeres con su destino y con su valor diferencial. 


\section{Notas}

1. El término en correlación debería ser matrimonio, pero "matrimonio" no se refiere a los bienes heredados de la madre, sino a la unión formal con un contrato con el cual la mujer se une al hombre y trae sus bienes a la familia del novio.

2. Nace en 1943 y se inicia en el Círculo de Poetas Costarricenses, a la par de Laureano Albán y de Jorge Debravo, entre otros. En 1968 gana el Premio Aquileo Echeverría en la rama de poesía con su segundo poemario El peso vivo, mientras que en 1975 obtiene el Premio Editorial de Costa Rica en poesía con el libro Los pasos terrestres. Recientemente, su poemario Casas de la memoria gana el premio Editorial de la Universidad de Costa Rica 2000.

3. Tendemos por ello a borrar las fronteras entre brujería y hechicería. Sin embargo, en sentido estricto, la brujería estaría como práctica ligada a la magia negra y el culto al demonio, mientras que la hechicería no.

4. Llama poderosamente la atención la manera en la que Dobles describe el aquelarre en forma de imágenes visionarias a las que yuxtapone percepciones, como por ejemplo en "la luna silente", en donde "silente" se refiere a la noche o en "fuego receloso", en donde "receloso" caracteriza más bien el comportamiento de las hechiceras.

5. Es religiosa en su sentido primigenio, de religare en latín, que significa “unirse a”. El ritual del aquelarre busca la manifestación de lo sagrado.

6. En este último par existe una inversión, ya que se presenta en primer lugar el elemento negativo.

7. Recordemos que no son los únicos; la Inquisición nace para combatir las heterodoxias religiosas y está presta a condenar a las marginalidades religiosas y sexuales, de todo aquello que estuviera fuera de la norma social; de ahí su efecto sancionador, con castigos y penas incluidos.

8. Agrega al respecto Kamen: “[...] se les daba siempre a elegir entre arrepentirse antes de que el auto de fe alcanzara su punto culminante, en cuyo caso eran 'misericordiosamente' estrangulados cuando se iban a encender las llamas, o a no arrepentirse, en cuyo caso eran asados vivos" (1985: 248).

9. En 1486, los dominicos alemanes Heinrich Kramer y Jacob Sprenger escriben un manual para inquisidores, con el fin de que sepan detectar a las brujas y la manera en la que deben combatirlas. En este manual, la bruja se asocia a un conocimiento prohibido y maléfico, la perdición del hombre como la Eva mítica que nos hizo comer del fruto prohibido; ése es el origen de la brujería, la perversión y la maldad de la mujer.

10. Nos referimos al mito de Inanna dentro de los sumerios o a Deméter entre los griegos.

\section{Bibliografía}

Bajtin, Mijail. 1980. Estética de la creación verbal. México: Siglo Veintiuno Editores.

Baeza Flores, Alberto. 1985. "Un diestro roce de fogatas". "Suplemento Áncora”, La Nación, domingo 17 de marzo: $1 \mathrm{D}$. 
Balcells, José María. 2003. "El mito del origen en la poesía de Juana Castro”. Estudios Humanísticos, Filología. 25: 175-83.

Caro Baroja, Julio. 1961. Las brujas y su mundo. Madrid: Revista de Occidente.

Chen Sham, Jorge. 2001. "La plegaria poética y la unión sagrada en los últimos poemas de Eunice Odio”. En: Jorge Chen Sham y Rima de Vallbona (Eds.): 207-28.

Chen Sham, Jorge y Rima de Vallbona (Eds.). 2001. La palabra innumerable: Eunice Odio ante la crítica. San José: Editorial de la Universidad de Costa Rica/ Instituto Literario y Cultural Hispánico.

Chevalier, Jean y Alain Gheerbrant. 1995. Diccionario de los símbolos. 5a. edición. Barcelona: Editorial Herder.

Chinchilla Sánchez, Kattia. 1998. “Las brujas de Salem de Arthur Miller”. Káñina. 22 (1): 139-48.

Dobles, Julieta. 1986. Los delitos de Pandora. San José: Editorial Costa Rica.

Guerra, Lucía. 1994. La mujer fragmentada: Historias de un signo. La Habana: Ediciones Casa de las Américas/ Colcultura.

Gumbrecht, Hans Ulrich. 1979. "Persuader ceux qui pensent comme vous: Les fonctions du discours épidictique sur la mort de Marat". Poétique. (39): 363-84.

Hutchinson, Steven. 1992. "Las brujas de Cervantes y la noción de comunidad femenina". Bulletin of the Cervantes Society of America. 12 (2): 127-36.

Kamen, Henry. 1985. La Inquisición española. Barcelona: Ediciones Crítica.

Kristeva, Julia. 1993. Historias de amor. 4a. edición. México, D.F.: Siglo Veintiuno Editores.

Prada Oropeza, Renato. 1990. “Constitución y configuración del sujeto en el discurso testimonio”. Casa de las Américas. 30 (180): 29-44.

Zavala, Iris M. 1996. "Las formas y funciones de una teoría crítica femenista. Femenismo dialógico”. En Iris Zavala (Coord.): 27-76.

(Coord.). 1996. Breve historia feminista de la literatura española (en lengua castellana). Tomo I. La mujer en la literatura española (Modos de representación desde el siglo XVIII a la actualidad). Barcelona-San Juan: Edit.Anthropos/ Universidad de Puerto Rico. 